\title{
Living in Plurilingual Spaces: Self-Study, Critical Friendship, and the Plurality of Publics
}

\author{
Cécile Sabatier $^{\mathbf{a}}$ and Shawn Michael Bullock ${ }^{b}$ \\ ${ }^{a}$ Simon Fraser University, Canada; ${ }^{b}$ University of Cambridge, UK \\ *Corresponding author. Email: sabatier@sfu.ca
}

\begin{abstract}
In this article we engage in collaborative self-study through a critical friendship that is specifically designed to evoke our personal histories in relation to how we approach our practices as teacher educators. In particular, we focus on understanding the conceptual origins of our pedagogies of teacher education and how our identities as teacher educators were shaped, and continue to be shaped, by colleagues, teacher candidates, and by the process of self-study itself. We argue that the multiple studies that are available to any self-study research program creates a plurality of publics in which we identify, and are identified, in particular ways by particular members of the teacher education community. One significant avenue for our developing line of work concerns the ways in which our shared bilingualism plays out during our critical friendship, and how the use of multiple languages helps us to reframe our identities as teacher educators, particularly whilst engaged in translanguaging practices.
\end{abstract}

Keywords: plurilingualism, critical friendship, personal history, self-study, $l a$ didactique, reflective practice

In the inaugural issue of our flagship journal, Studying Teacher Education, Loughran (2005) opined that, while there is no one way to conduct self-study research, there is a broadly defined coherence to the nature and purpose of the work. Self-study of teacher education practices is, by and large, considered a methodology that encourages teacher educators to describe, interpret, and analyse the sources and effects of their pedagogies of teacher education. In so doing, self-study researchers are called on to make an ontological commitment (Pinnegar \& Hamilton, 2009) to the work by examining their selves-in-relation to practice, to their teacher education students, to their personal histories, and to their developing identities.

A perennial challenge for any scholar who is new to self-study work is to find ways to situate themselves within self-study methodology and literature given their prior academic knowledge. This challenge is amplified, we believe, for researchers who have trained outside of the Anglophone academy, who might find it difficult to see their academic traditions represented in self-study literature, which is largely (although not exclusively) grounded in the North American and Australian academic traditions. Calls for increasing the diversity of voices within the self- study community have abounded for many years, and much important work has been done in this regard (e.g., Tidwell \& Fitzgerald, 2006; Kitchen et al., 2016). We take such calls seriously by attending to the linguistic diversity and different academic training of the authors as we explore the ways in which our academic backgrounds, first languages, and personal histories shape (and have shaped) who we are as teacher educators.

Cécile is an experienced academic who received initial academic training and socialization in France. She is new to self-study methodology but is fully grounded in a theoretical framework, la didactique du plurilinguisme (Coste \& Simon, 2009; Dabène, 2003) [didactics of plurilingualism - a sociolinguistic and sociodidactic theory that developed initially in the 1960 s as a response to the hegemonic structures facing multiple language 
learners in France], that has not been taken up in a significant way in Anglophone academies (Moore \& Gajo, 2009). Shawn is also an experienced academic; although he found self-study methodology (LaBoskey, 2004) as a doctoral student in Canada and made it the primary methodological focus of his academic work. For most of his career, he would have mostly identified himself as a science and technology teacher education specialist, although he has recently made a turn in his work to language education. We both taught at the same Faculty of Education at a Canadian university for 5 years; one in French and one in English. We are uniquely suited to be critical friends (Schuck \& Russell, 2005) due to shared passions for teacher education in scholarship and practice, in part due to our recent work participating in the re-design of a teacher education program, our work in language teacher education policy and practice (Bullock, 2018; Sabatier et al., 2017), and our shared interest in the nature and development of knowledge of teaching, albeit from perspectives developed in different crucibles of experience.

This paper marks the beginning of our commitment to take seriously LaBoskey's (2004) assertion about the importance of making knowledge gained through self-study subject to public scrutiny. As a beginning, we found it important to return to our academic first principles, our formations as scholars, as an initial catalyst for our self-study work and as a way of framing initial conversations. The results ended up including not only a reexamination of long-held beliefs about our identities as language teacher educators, but also the role of concepts such as code-switching, translanguaging, and plurilingual competence in our own work.

\section{Self-Study of Teacher and Teacher Education Practices}

Self-study methodology is "a body of practices, procedures, and guidelines used by those who work in a discipline or engage in an inquiry" (Samaras \& Freese, 2006, p. 56). Our mutual commitment to helping teacher candidates name, interpret, and analyse their learning experiences in their teacher education program has been the foundation of what Pinnegar and Hamilton (2009) have referred to as the "ontological commitment" of self-study researchers. We are mindful of Bullough and Pinnegar's (2004) discussion of the "four perplexing clusters of problems for self-study," which are the problems of definition, ontology, form, and scholarship (p. 340). We see these problems as highlight interrelated; our shared background in continental philosophy shapes our ongoing interest in returning to problems of definition and ontology in particular. Ontology, for example, can be defined in at least four ways according to Hofweber (2018); we find his summation of the challenges of ontology (and thus, presumably, ontological commitment) particularly useful: "Ontology is thus a philosophical discipline that encompasses besides the study of what there is and the study of the general features of what there is also the study of what is involved in settling questions about what there is in general, especially for the philosophically tricky cases." Self-study methodology offers, in our view, a cornucopia of "tricky cases," which, in turn forms what Bullock (2009) has referred to as a "basis-for-knowing."

We define collaborative self-study as methodology, a "basis-for-knowing" (Bullock, 2009) and a space for developing professional knowledge about teaching teachers. One important feature of the kind of self-study work that resonates with both of us is the potential of critical friendship for encouraging the kind of rigorous examination of identity, practice, and pedagogy that we believe is necessary to further our growth as teacher educators. Critical friendship, which is both a way of advocating for the success of one another's work (Costa \& Kallick, 1993) while providing a means to "negotiate [our] shared understandings of how [our] students become teachers and how teachers improve" (Schuck \& Russell, 2005, p. 119) seems fundamental to both personal history work and collaborative self-study more generally. It is, for us, a way of establishing trustworthiness in the academic sense of the 
term, as framing critical friendship as a central feature of self-study goes a long way to helping self-study researchers navigate that balance that Bullough and Pinnegar (2001) spoke of when they framed self-study at the intersection of biography and history. They argued, in part:

It is the balance between the way in which private experience can provide insight and solution for public issues and troubles and the way in which public theory can provide insight and solution for private trial that forms the nexus of self-study and simultaneously presents the central challenge to those who would work in this emerging area. (p. 15)

We take their argument that self-study sits at a nexus between personal and public seriously and find resonance between this tension and the moral commitment that Pinnegar and Hamilton (2009) spoke of. Given that our self-study was not only collaborative, in the sense that we co-authored this article, but also relied on the methods of personal history and discourse analysis for data collection, we quickly decided that the tradition of critical friendship would be an important framing position for our work together. Although the concept of critical friendship is somewhat loosely defined in some of the self-study literature, particularly with respect to the differences between critical friendship and collaborative selfstudy, we found the trust required of critical friends to be an absolutely crucial part of not only the initial study, but also the ways in which we reframed our learning about teaching teachers and the ways in which we prepared for our presentation at the Castle Conference in 2018. It was this trust that allowed us to ask difficult questions that required us to each live in somewhat uncomfortable spaces in our work together. The kind of honesty and willingness to manage difficult conversations displayed in Schuck and Russell (2005) resonated with our experiences somewhat and, in hindsight, were crucial to establishing trustworthiness on our work together.

\section{Objectives of the Study}

Our current research program explores the intersections between Francophone and

Anglophone traditions of reflective practice, reflexivity and, more specifically for this article, currently seeks to contribute to self-study methodological literature by introducing ideas and frameworks from theories of didactic interaction from the French academy. We believe that the best way to re- theorize about self-study in light of other frameworks is to engage in collaborative self-study that is specifically designed to evoke our personal histories in relation to how we approach our practices as teacher educators. In particular, this article focuses on:

1. Using personal history (Samaras et al., 2004) approaches to self-study in order to understand the conceptual origins of our pedagogies of teacher education and, in so doing, consider how our identities as teacher educators were (continue to be) shaped through interactions with teacher candidates and with colleagues.

2. Interpreting our personal histories to discover how self-study methodology might enhance our understanding of the theoretical frameworks that guide our pedagogical approaches ( $\mathrm{La}$ didactique du plurilinguisme and Schön's (1983) views on reflective practice) and, in turn, how these frameworks might enhance our conceptual interpretation of self-study methodology.

\section{Methods}

Samaras et al. (2004) asserted that a wide variety of qualitative methods tend to be used in personal history self-study while arguing that, generally, personal history self-study is valuable for "self-knowing and forming - and reforming - a professional identity, modelling and testing effective reflection; and, pushing the boundaries of teaching" (p. 913). We see our 
work as inexorably linked to these three ideas with a particular emphasis on identity at this stage. Our data sources were two-fold: audio recordings of regular meetings between the two authors and journals in which we recorded our thoughts in between meetings. Our usual, but not exclusive, practice was to begin our meeting by responding, in writing to the other person's journal. Our meeting then focused on expanding on these ideas through dialogue, as we both sought additional clarification both about what the other person wrote and about our own initial responses. Subsequent meetings often began with revisiting a key idea that was stimulated by a conversation in the previous meeting, since we both had time to consider our conversations more fully.

The data were analysed with a view to identify turning points (Bullock \& Ritter, 2011); of particular importance were turning points that revealed a new way of thinking about our personal histories and their impact on how we have framed ourselves as teacher educators in reaction to particular problems of practice. One characteristic of the two turning points that we report here is the affective dimensions of the data. This aligns significantly with Bullock and Ritter's (2011) and suggests that, at least in part, we fulfilled Pinnegar and Hamilton's (2009) requirements to make our work personal so that something was genuinely at stake.

One unique feature of our work is that both verbal and written data were created in French and English, as felt appropriate to each author and within each situation. Freely communicating in either language was one of the ways in which we recognized the diversity that exists between our authorship, and we hope that this style might provide some insight into conducting self-study methodology across cultural and linguistic boundaries. Although this chapter is written in English, we feel it is important to recognize the ways in which our choices of language shape and influence how we think. Much has been said, particularly over the past few years, about diversifying the self-study research community in a number of ways. We believe that making explicit our linguistic practices, which helps to ensure each author has the opportunity to communicate their experiences that feel most comfortable at the time, is one way of enhancing the diversity of self-study work. Further, we wish to highlight that the way we communicate is not simply a matter of Cécile speaking French whilst Shawn speaks English, although that does happen (minimally) from time to time. We both tend to speak the same language to each other at a given moment, and one follows the other in a "code-switch" from one language to the other and back again. We have only begun to theorize why we might switch from one language to another within the context of self-study; although we are convinced it is a fruitful future line of inquiry. We wonder, specifically, about the effect that this ability to follow each other through Schön's (1983) swampy lowlands of practice in each other's first language.

\section{Outcome 1. Navigating Sub-Identities; Becoming Insider-Outsiders}

Swennen, Jones, and Volman (2010) argued, in part, that becoming a teacher educator requires one to navigate multiple "sub-identities": school teacher, teacher in higher education, teacher of teachers, and researcher. Our collaborative self-study contributes to this kind of broad teacher education literature by shedding light on how our sub-identities as teachers of teachers and prior academic socialization as researchers in different contexts to the ones in which we now teach have had an impact on our pedagogies of teacher education. Furthermore, our work contributes more specifically to self-study literature: Skerrett (2008), for example, called attention to the challenges of teaching future teachers when one comes from a non-dominant culture. Cécile comes from France, a minority culture in Canada, and is asked to teach future teachers of French - some of whom come from other French-speaking parts of Canada and some of whom speak French as an additional language. Shawn recently began a new position at a university in which he is the only Anglo-Canadian member of the 
Faculty of Education. The politics of teaching in and teaching about French and English within Canada and in Europe figure heavily into our self-study work - they are indeed "tricky cases."

Although we sensed initially that language and culture would play a role in our work, our first self-study conversation began with a call to understand more clearly what is meant by the term "self" in self-study. Initially, we spoke about the difference between understanding our "professional self" and our "personal self", and indeed the importance of recognizing multiple selves in relation to our practices and our identity development. With the benefit of hindsight, we realize that perhaps this was a way of finding out whether or not we were both willing to return to the first principles of our academic understandings. We were. The notion of plurality of selves would become more important during our Castle Conference presentation but, a baseline established, our conversation turned to ways in which we had felt excluded in our prior work as teacher educators.

Although both of us taught in the same Faculty of Education and both of us have taught in the K-12 system, we neither completed our teacher education program nor taught within the local context in British Columbia. This outsider status was, to our surprise, felt by both of us, albeit in different ways. Cécile related a story in which, early in her career at the university, she was asked to introduce herself to a group of teacher candidates. She responded by introducing her professional qualifications and the frameworks in which she worked; as is customary in France. A seconded teacher working within the teacher education program, somewhat dismissively, stated in response: "Yes...but who are you?" Cécile was unused to being asked to define her identity to teacher candidates in this way. She had a definition of identity imposed on her by the discourse community (Gee, 2000) of the faculty-there was clearly an accepted way to talk about who one is as a teacher and it did not match her initial expectations. To be asked a question of "Who are you?," in that fashion, implied that her response was somehow lacking in substance and that she had thus failed to cross the border from education professor "from abroad" to teacher educator at SFU.

It was not until our collaborative self-study that Cécile realized - to her great surprise - that this sense of malaise was not due to "Canadian culture" but to the local context, as Shawn clarified his own, similarly problematic experiences. Shawn frequently commented on his lack of insider status due to the fact he was educated and taught in Ontario; the implication from more than a few teachers has been that his expertise was limited having never taught in a school district local to their university. The sense of a professional identity crisis culminated in seeking recognition of his Ontario teaching credentials in British Columbia, as a way of proving, in effect, that he had the same right to be in K-12 schools. Interestingly, Shawn returned to the same pattern after moving to the U.K.: he immediately sought out and received his qualified teacher status (QTS) in the U.K. Similarly, Shawn commented on the much more profound interest that the Faculty we worked at together seemed to have in non-discipline based holistic approaches and, perhaps as a result, to talking far more openly about identity/ies with teacher and experienced teacher candidates. He remarked that the teacher education program, at the beginning of his time at the Faculty, seemed to him to be fundamentally about developing an identity as a teacher. The lack of focus on content and what might be termed pedagogical content knowledge (Shulman, 1986) was something he was unused to from his experiences in the province of Ontario. Whilst in other faculties he had openly critiqued a lack of attention to development of teacher voice, he felt that the current teacher education program had forgotten all other elements of teacher education. Like Cécile, he felt that his formation in education outside of the province had framed him in particular ways in eyes of colleagues and, in particular, he was keenly aware of being perceived as overly formal and unwilling to talk openly about his identity as a teacher educator. 
As Cécile noted: "Our teacher education program has its own discourse and a way of doing things; insider or outsider, you have to make a choice. The Faculty Associates [seconded local teachers, with whom we work] make that choice on our behalf; they tell you if you belong or not." Shawn responded: "It has been pre-decided what topics a professor is 'qualified' to talk about... we are outsider-insiders, or insider-outsiders." Cécile expressed her frustration with the way she has been portrayed to teacher candidates by Faculty Associate colleagues from time to time, recounting a moment just before she was to teach a group of teacher candidates:

I was getting ready to begin my lesson when a teacher candidate said, ' $T u$ vas nous illuminer aujourd'hui? [You are going to enlighten us today?]. The origin of this particular framing was clear to me." Opposing a 'we' referring to the teacher candidate community to a 'you' referring to Cécile sets up a power dynamic. The outsider status conferred by this teacher candidate on Cécile unveils an inherent complexity in the relationships between teacher candidates and teacher educators where a power is framed in a particular way - to say nothing of the fact that the teacher candidate immediately used the informal "tu" subject with a university professor that they did not know - something unlikely to happen in France. In this instance, a delineated boundary has been drawn reproducing an authoritative discourse unquestioned by the teacher education community at the university at large. As Merriam et al. (2001) stated, "Positionality, power, and representation proved to be useful concepts for exploring insider/outsider dynamics" ( $p$. 405).

Years later after the incidents we recounted to one another during our conversations, we realize that we have both navigated new sub-identities in response to institutional identity cultures and prevailing discourses within the program. For example, although Shawn still considers himself much more focused on the pragmatics of learning to teach from disciplinary-based experiences than many colleagues, the discourse communities have encouraged him to articulate some of the ways in which his personal identities have contributed to professional identities. He has written elsewhere (Bullock, 2014) about the vulnerability he felt revealing to teacher candidates the degree to which his practice of martial arts influenced his pedagogical stance; that vulnerability has since led to multiple academic publications and, significantly, a willingness to engage with the martial arts teaching community as both a martial arts teacher and an education professor, instead of solely as an insider. More recently, he has spoken - for the first time in his life-openly to large groups of teacher candidates about his experiences being identified as a student with "special needs" - and the associated problems of how he was framed as a student as a result.

\section{Outcome 2. Foundations and Formations}

The second significant outcome in our work is the degree to which our formation as scholars in graduate school continues to shape how we see ourselves as teacher educators and, in many ways, serves as conceptual rudders during the turbulent waters of teacher education. In this work, we focus on the possibilities of la didactique du plurilinguisme and reflective practice for understanding our selves-in-practice as teacher educators.

During our first meeting, Cécile and Shawn realized that, despite being new to selfstudy, Cécile had an intuitive understanding of many of the issues of the importance of understanding self-in-practice as a result of her formation in la didactique $d u$ plurilingualisme. The theory exists at the intersection of sociolinguistics and sociodidactics (Dabène, 2003). Its founders were fundamentally interested in multiple language learners and the associated challenges they encountered with the hegemonic structures of the existing educational system. La didactique du plurilinguisme helped to focus on the relationships between teachers and learners as social actors within an overall societal structure that, 
particularly in the 1960s and 1970s, tended to frame multilingual learners as a problem to be solved in contemporary classrooms (Blanchet 2007; Dabène, 2003; Galisson, 1989). Its purpose is to question the nature of teaching and learning - that is, what there is, in relation to socialisation and individualisation in "a web of complex and interacting pluralities" (Coste \& Simon, 2009). It supports the idea that both education and teacher education can work towards understanding the complexity of issues concerning plurality by a host of embodied experiences, such as life histories and multiple identities. It offers, in our view, a productive, and vastly under-utilized, frame of reference describing, interpreting, and analysing research on teacher education.

Before beginning our first meeting, Cécile's first line in her research journal was "Who am I as a teacher educator?" She thus began from a stance of examining her conceptual foundations of practice as a teacher educator and, in a significant moment, was motivated to create a diagram of a tree to explain the intersections of her research interests and her formation as a scholar. Although it had always been clear to Cécile that she was educated in la didactique du plurilinguisme, it was less clear to her how much her scholarly interests in issues of, for example, social justice for minority language learners transversed the boundaries of la didactique du plurilinguisme. Her insight was: "The 'pluri' in plurilinguisme has always called me to take multiple approaches to a given problem ... in effect, everything has become a plural. For this reason, I understand why I prefer to think of the power of study of multiple selves in self-study, and why I tend to say self-studies instead of self-study when I speak in English.”

After a few meetings, Shawn commented on Cécile's tendency to use the term selfstudies, even when we spoke in French, as opposed to étude du soi. Although he understood that leaving the term in English was a way to acknowledge its origins, he was intrigued by Cécile's choice to say self-studies as opposed to self-study, a plural instead of a singular. Acting as "a sounding board" (Schuck \& Russell, 2005, p.107), Shawn's remark supports Cécile's reframing of her foundations as it made her aware that she has "always worked on and with plurality" since the beginning of her foundational work. Plurality is deeply embedded in Cécile's study of (her) selves. It is at "the core of [her] vision of the world, of the Self. We are multiple; we play with the different facets of who we are; this plurality manifests in our practice which in turn reflects in our Self and is a window to our selves." As Lahire (1998) argued, embracing the multiple dimensions of the selves within one self leads to recognise individuals as the primary actors of their actions. To do so requires not only selfstudy of multiple selves, but multiple studies of an elusive, plural self. Cécile's insight provided a moment for Shawn to reframe his idea of self-study methodology as well; giving him the idea that embracing the multiplicity of "studies" in self-study provides one way of responding to critiques that self-study does not build on its own work.

Cécile's comments take us back to a consideration of her foundational educational experiences in la didactique. By focusing on learners and teachers as actors of social change, la didactique du plurilinguisme offers an interesting framework to anchor the study of the Self, or, in our view, Selves in relation to others and to practice. In contexts of diversity, an increasing number of students and teachers speak different languages at home and at school. How do they make sense of these identities? How do we, as teacher educators, take these identities into account in our pedagogy? How do we take into account these multiple selves? How are these selves shaped by the language(s) we use to speak about them?

Shawn's experiences thus far in the self-study have encouraged him to analyse carefully the conceptual foundations with which he approaches problems in and experiences with teacher education. The act of re-interpreting Schön (1983), in particular, with Cécile made him wonder about the degree to which he needs to be more explicit about the language he uses to think about his classroom interactions with teacher candidates and, as a result, the way he 
teaches about thinking about classroom interactions in the K-12 system. Concurrent with Bullock (in press), this new work underscores Shawn's lifelong, but problematically tacit, interest in and engagement with and from language education. Despite attending to the use of conceptual metaphor (Lakoff \& Johnson, 1983) as a way of analysing classroom interactions for the bulk of his career, Shawn seems to have heretofore lacked the confidence to strongly situate himself within language education. An exploration of the social implications of $l a$ didactique du plurilinguisme, which addresses both some of his longstanding concerns in Anglophone literature and the bilingual nature of this self-study has been, in many ways, the beginning of a re-formation rather than a re-assertion of his initial formation as a doctoral student and new academic.

\section{The Plurality of Publics: Towards Self-Studies}

Our self-study began as a way to understand the foundational theoretical frameworks on which we have constructed our respective careers and, in so doing, analyse and interpret the ways in which these frameworks shaped (and continue to shape) our pedagogies of teacher education. We also explored the possibilities of boundary-crossing, both linguistically and in a scholarly sense, to understand how we might imagine possibilities for ourselves as teacher educators.

By exploring our multiple sub-identities, we underscored the "trickiness" of positioning oneself (and/or being positioned by others) when we engage in reframing our practice. Layering our several selves led us to question the foundations of our own practice in teacher education. Samaras et al. (2004) cautioned that personal history self-study "is a way to put that [teacher educator] identity on the line and risk needing reform and recreate the self while also attempting to transform curricula." (p. 915). Our collaborative work makes us wonder whether identities of teacher educators should ever be considered in isolation, as the often-emotive nature of our work - particularly whilst sharing personal histories fraught with senses of being outside a narrative - seems ideally suited to work with a critical friend. We remain mindful that "what we publicly reveal about our practice must further the cause of teacher education" (Bullough \& Pinnegar, 2004, p. 340).

In this spirit, we offered the notion of plurality to the self-study community as a major outcome to our consideration of the "tricky cases" encountered in our personal histories, in anticipation of the Castle Conference in July 2018. Although we are certainly not the first in the community to speak of pluralities, we do offer the idea of Cécile's notion of self-studies as a fundamentally revealing characterization of the multiple tensions encountered in our practices. We demonstrated moments where we were called to cross boundaries in difficult situations to create new sub-identities and that self-study can shed multiple understandings on old, deeply held initial scholarly formations. Loughran (2005) once cautioned about the problematic naming of self-study, particularly that notions of self conjure up image of solipsism. Perhaps the singular "study" is subject to the same challenges. Our next challenge would be to highlight this plurality during our Castle Conference presentations

\section{Insights from the Castle Conference Presentation}

Drawing from a current (yet recurring) desire to better understand "issues related to establishing and articulating the theoretical (epistemological, pedagogical, and moral) and methodological foundations of self-study" (Bullock \& Peercy, 2018, p. 20), we decided to take this question - should we talk about selves-study or self-studies? - to our audience when we presented at the $12^{\text {th }}$ Castle Conference, in July 2018. In doing so, we discussed the challenges, the tensions, and the "trickiness" we faced by developing new understandings about self-study methodology and our practice. As with all Castle Presentations, the 
challenge was to, as far as possible, create an experience for our audience related to our article that they could participate in, rather than simply tell them about our insights.

The starting point of our Castle conference was an opening conversation between the two of us in order to engage our public, as critical friends, in discussing the origins and the consequences of these in our pedagogies as teacher educators. Right from the start, we wanted to draw attention on the nuances, opportunities, and challenges of conducting a selfstudy situated in theoretical frameworks built in different academic traditions and in a bilingual mode. This mode of interaction suggests that the two languages we share (French and English) play an equal part in constructing our understanding of our pedagogies of teacher education and, crucially, our understanding of what self-study is about. Indeed, when we started our collaboration, Cécile's very first question was: "What language do I write in?" This matter was of importance not only because of Cécile's foundations in la didactique du plurilinguisme, but also because the circulation of ideas, concepts and notions, from one framework to another, from one language to others, lies in the ways in which these ideas, concepts and notions are transformed by the different linguistic and intellectual traditions (Zarate \& Liddicoat, 2009).

Questioning how the studies of our selves are and have been shaped by the language(s) we use in order to learn more about our pedagogies led us to emphasize when and why both of us codeswitched from one language to the other. And so, during our opening conversation, each of us re-enacted one of our regular meetings, insisting on the ways our bilingual interactions shaped our critical friendship's talks. The only substantive difference to this conversation (other than the obvious artificiality of performing at a conference) was that we both tried to keep language use at 50-50 between French and English, something we would not normally do. Our re-enactment created a window into our free crossing of languages; we made clear that French was not only used by Cécile but Shawn too codeswitched into it. We highlighted that Cécile's use of English was a way for her to distance herself from any "tricky" topic in considering her pedagogy of teacher education, as using English helped to remove some of the emotional nuance of what she was interested in discussing. At the same time, switching to French sometimes served as a tacit call for Shawn's help to process the new learning. In this instance, Shawn was seen as a trusted person, a supportive friend, "an advocate for the success of that work" (Costa \& Kallick, 1993, p. 50, in Schuck \& Russell, 2005, p. 108). Our attention to the languages we used to conduct our self-study has not emerged at the Castle conference, though; it was reinforced by attending several other presentations and by questioning how our code switching (alternating from one language to the other) and our translanguaging (a dynamic process whereby multilingual speakers use all the linguistic resources of their linguistic repertoire as an integrated communication system; Garcia and Wei, 2014; Lewis, Jones \& Baker, 2012) helped us to navigate the intellectual borders to make sense of our selves. Put simply, yet in a way that obfuscates the complexity of our processes: we use whatever linguistic tools that are at our disposal to try to get to the heart of what we are curious about.

For Cécile, crossing these linguistic and intellectual borders appeared to be easier than crossing the boundaries of how to engage oneself/herself within the self-study community. Crossing the boundary of a new academic community appeared to be challenging and full of tensions for both of us. On the one hand, Cécile, a newcomer to self-study methodology and Castle presentations, struggled with the introduction to our presentation that Shawn suggested. It was a tall order: Improvise a conversation that was partially in a language Cécile was unaccustomed to using in academic contexts. Shawn, in contrast, had considerable experience as a self-study researcher and presenter and, as he has written about elsewhere, has trained in improvisational theatre. What Cécile perhaps did not realize at the time was the pressure of using academic French in front of a crowd, even if most were unlikely to speak 
the language. Although Shawn has long been accustomed to speaking French with Cécile, the idea of speaking a second language to a community that had, likely, positioned him as a monolingual anglophone for over a decade was a bit daunting. As a part of this study and this presentation, Shawn has realized that he has, in many ways, masked his bilingualism for many years due to frustrations around his accent and, perhaps, as a remnant of embarrassment he used to feel when he had a significant stuttering problem in the early years of elementary school.

Thus the opening conversation, fully improvised, in Cécile's second language challenged Cécile's perceptions of herself as a (self-study) researcher. Feeling insecure as a second language speaker, afraid of not being able to make sense in her other language, Cécile's representation of self seemed at this moment overcome by the question of languages. She was no longer a competent experienced researcher; she was just a second language speaker making a presentation on a topic that suddenly felt even more different. Shawn, an established figure in the field, accustomed to self-study methodology and presentations at Castle conferences, was willing to recognize and help Cécile to name the tensions she was feeling. Although he was more than willing to do a different sort of presentation that did not rely on improvisation, he clearly stated to Cécile that he felt she would learn more with the improvised conversation. He also wanted this tension to be a professional learning experience. Cécile felt that Shawn was patient throughout the process although he asked frank but provocative questions that pushed her to the limits of her comfort as an academic. One significant moment of reframing for both of us occurred after Cécile expressed frustration with feeling tense about presenting. Shawn stated: "It seems like everything comes back to identity/ies here, and renegotiating those identities." Both of us immediately saw that this was another example of how Cécile's initial formation in plural approaches to thinking about education affected every domain of her identity as an academic.

Shawn's positioning encouraged Cécile's reflection on how she would be able to carry out her own posture in the self-study community as well as in teacher education. By challenging the origins of her struggles as well as the consequences in her pedagogy, Shawn provided "trust, support, and flexibility [that] are essential elements of a critical friendship" (Schuck \& Russell, 2005, p. 112). He also pointed out some focal "turning points" (Bullock \& Ritter, 2011) in their collaboration that led him to overcome his own resistance to language education. As our preparation moved beyond tension around whether to improvise a conversation, and particularly after the presentation itself was over, Shawn was able to realize the extent to which he had resisted being labelled a language educator so strongly, to the point where he either actively used the term literacy instead or, in the most extreme case, played down his bilingualism, and the translanguaging practices he has engaged in during his whole career as a martial arts instructor.

The depth of insights we both gained by carrying our critical friendship process through a Castle Presentation speaks to the value of the unique format of the Castle: People come ready to talk, they can read your article, and they want to use the 50 minutes for more than a PowerPoint presentation. In this way, the community itself acted to augment the trustworthiness of our critical friendship and point us in new directions for our research.

Peercy and Sharkey (2018) made a strong case for the role that self-study research offers a way for the field of language teacher education (LTE) develop rich understandings of teacher educators as scholars, practitioners, and researchers, and that a failure to do so would result in "missing a S-STEP" (p. 1) in the knowledge base. They opined that S-STEP had not yet found a significant place in the broader LTE research community, despite the fact that SSTEP methodology seems to respond directly to critiques raised in a foundational article from a special issue of a major journal over 20 years ago (Freeman \& Johnson, 1998). Taking a cue from Peercy and Sharkey's recent work, we position our research — and its attendant 
insights from presenting at the castle conference - as partly responding to Peercy and Sharkey's concerns and partly bringing knowledge and ideas for LTE more directly into selfstudy research. We are not the first language teacher educators to work in self-study, but we would argue that an original feature of our work is that our theoretical framework, $l a$ didactique, comes from a different scholarly tradition than those usually found in anglophone academies. Coupled with our plurilingual approach to data gathering and analysis, we are able to more fully explore concepts such as code-switching, translanguaging, and plurilingual competence in our work as self-study researchers because these ideas are both objects of study and the ways in which we aim to understand who we are in how we teach future language teachers.

\section{References}

Blanchet, P. (2007). Légitimer la pluralité linguistique ? Pour une didactique socialement impliquée. In P. Lambert, A. Millet, M. Rispail \& C. Trimaille (Eds.), Variations au cour et aux marges de la sociolinguistique (pp. 207-214). Paris: L'Harmattan.

Bullock, S. M. (2009). Becoming a teacher educator: The self as a basis-for-knowing. In K. Pithouse, C. Mitchell, \& L. Moletsane (Eds.), Making connections: Self-study and social change (pp. 269-283). New York, NY: Peter Lang.

Bullock, S. M., \& Ritter, J. K. (2011). Exploring the transition into academia through collaborative self study. Studying Teacher Education, 7(2), 171-181.

Bullock, S. M. (2014). Exploring the impact of prior experiences in non-formal education on my pedagogy of teacher education. Studying Teacher Education, 10(2), 103-116.

Bullock, S. M. (2018). The accidental language teacher educator: Learning to be a language teacher educator within diverse populations. In J. Sharkey \& M. Madigan Peercy (Eds.), Self-study of language and literacy teacher education practices across culturally and linguistically diverse contexts (pp. 17-36). Bingley, UK: Emerald Publishing.

Bullough, R. V., Jr., \& Pinnegar, S. (2004). Thinking about the thinking about self-study: An analysis of eight chapters. In J. J. Loughran, M. L. Hamilton, V. K. LaBoskey, \& T. Russell (Eds.), International handbook of self-study of teaching and teacher education practices (pp. 313-342). Dordrecht: Kluwer.

Coste, D. \& Simon, D. L. (2009). The plurilingual social actor. Language, citizenship and education. International Journal of Multilingualism, 6(2). 168-185.

Dabène, L. (2003). From applied linguistics to sociolinguistics: A research itinerary. International Journal of the Sociology of Language, 160, 105-121.

Galisson, R. (1982). Problématique de l'autonomie en didactique des langues (Contexte français). Langue française, 82(1). 95-115.

Garcia, O. \& Wei, L. (2014). Translanguaging: Language, bilingualism and education. London, UK: Palgrave Macmillan.

Freeman D., Johnson K.E. (1998). Reconceptualizing the knowledge-base of language teacher education. TESOL Quarterly, 32, 397-417.

Hofweber, T. (2018). Logic and ontology. In E. N. Zalta (Ed.), The Stanford encyclopedia of philosophy. Retrieved from https://plato.stanford.edu/archives/sum2018/entries/logicontology/

Kitchen, J., Tidwell, D. L., \& Fitzgerald, L. M. (Eds.). (2016). Self-study and diversity II: Inclusive teacher education for a diverse world. Rotterdam, The Netherlands: Sense Publishers.

LaBoskey, V. K. (2004). The methodology of self-study and its theoretical underpinnings. In J. J. Loughran, M. L. Hamilton, V. K. LaBoskey, \& T. Russell (Eds.), International 
handbook of self-study of teaching and teacher education practices (pp. 817-870). Dordrecht: Kluwer.

Lahire, B. (1998). L'homme pluriel. Les ressorts de l'action. Paris, France: Nathan.

Lewis, G., Jones, B., \& Baker, C. (2012). Translanguaging: Origins and development from school to street and beyond. Educational Research and Evaluation, 18(7), 641-654.

Merriam, S., Johnson-Bailey, J., Lee, M.-Y., Kee, Y., Ntseane, G., \& Muhamed, M. (2001). Power and positionality: negotiating insider/ outsider status within and across cultures. International Journal of Lifelong Education, 20(5), 405-416.

Merton, R. (1972). Insiders and outsiders. A chapter in the sociology of knowledge. American Journal of Sociology, 78(1), 9-47.

Moore, D. \& Gajo. L. (2009). Introduction - French voices on plurilingualism and pluriculturalism: Theory, significance and perspectives. International Journal of Multilingualism, 6(2).137-153.

Peercy, M. M., \& Sharkey, J. (2018). Missing a S-STEP? How self-study of teacher education practice can support the language teacher education knowledge base. Language Teaching Research, 1-11.

Pinnegar, S., \& Hamilton, M. L. (2009). Self-study of practice as a genre of qualitative research. Dordrecht: Springer.

Sabatier, C., Spiliotopoulos, V., Leger, R. \& Pajot, D. (2017). (trans. S. M. Bullock \& C. Sabatier). French as a second language education and British Columbia's second language education policy. Victoria, BC: Ministry of Education.

Samaras, A., Hicks, M., \& Berger, J. (2004). Self-study through personal history. In J. J. Loughran, M. L. Hamilton, V. K. LaBoskey, \& T. Russell (Eds.), International handbook of self-study of teaching and teacher education practices (pp. 905-942). Dordrecht: Kluwer.

Schuck, S., \& Russell, T. (2005). Self-study, critical friendship, and the complexities of teacher education. Studying Teacher Education, 1(2), 107-121.

Skerrett, A. (2008). Biography, identity, and inquiry: The making of teacher, teacher educator, and researcher. Studying Teacher Education, 4(2), 143-156.

Swennen, A., Jones, K., \& Volman, M. (2010). Teacher educators: their identities, subidentities and implications for professional development. Professional Development in Education, 36(1-2), 131-148.

Tidwell, D., \& Fitzgerald, L. (2006). (Eds.). Self-study and diversity. Rotterdam: Sense.

Zarate, G., \& Liddicoat, A. (2009). La circulation internationale des idées en didactique des langues [International circulation of ideas in language teaching/learning]. Le Français dans le Monde-Recherches et Applications, 46. 